Sex selection

\title{
Can sex selection be ethically tolerated?
}

\section{B M Dickens}

\section{Prohibition on sex selection may well be unnecessary and oppressive as well as posing risks to women's lives}

$\square$ he urge to select children's sex is no new. The Babylonian Talmud, a Jewish text completed towards the end of the fifth century of the Christian era, advises couples on means to favour the birth of either a male or a female child. The development of amniocentesis alerted the public in the mid-1970s to the scientific potential for prenatal determination of fetal sex, ${ }^{2}$ and progressive decriminalisation of abortion afforded choice about continuation of pregnancy. The more recent emergence of preimplantation genetic diagnosis (PGD) obviates resort to abortion, and improved techniques of sperm sorting and diagnosis permit creation of zygotes that will ensure the sex of a future child

Growth of biomedical means to select the sex of future children has been accompanied by fear that such means will be employed to favour births of sons, and so perpetuate devaluation of girl children and women's inferior family and social status. A reaction to this fear has been the demand for legal and medical professional prohibition of sex selection techniques. For instance, the Council of Europe's Convention on Human Rights and Biomedicine ${ }^{3}$ provides in article 14 that:

\begin{abstract}
The use of techniques of medically assisted procreation shall not be allowed for the purpose of choosing a future child's sex, except where serious hereditary sex-related disease is to be avoided.
\end{abstract}

Legislation has been enacted in a number of countries, and proposed in others, to prohibit sex selection on non-medical grounds, such as the Prenatal Diagnostic Techniques (Regulation and Prevention of Misuse) Act, 1994 in India. In Canada, for instance, government draft legislation introduced in May 2002 proposes to make it a crime for any person, for the purpose of creating a human being, knowingly to:

perform any procedure or provide, prescribe or administer any thing that would ensure or increase the probability that an embryo will be of a particular sex, or that would identify the sex of an in vitro embryo, except to prevent, diagnose or treat a sex linked disorder or disease. ${ }^{4}$

In light of evidence from India, China, and other countries and cultures in which son preference is apparent, many analysts and commentators have envisioned the use of techniques of sex selection only as reinforcing male dominated sexism and women's subordination.

New reproductive techniques and technologies have always triggered fears of unnatural, harmful outcomes, social disruption, and destruction of conventional families. In the mid-1960s, addressing human reproduction by artificial insemination, the gynaecologists Kleegman and Kaufman perceptively observed that:

\section{Any change in custom or practice in this emotionally charged area has always elicited a response from established custom and law of horrified negation at first; then negation without horror; then slow and gradual curiosity, study, evaluation, and finally a very slow but steady acceptance. ${ }^{5}$}

The established custom that was initially, and in some cases is still, horrified at recognition of the potential for effective sex selection of future children was not only that of conservative religion, but also that of some components of organised feminism. By the 1980s, feminism was becoming a politically influential force in Western Europe, North America, Australia, and several other westernised democratic countries. ${ }^{6}$ The dilemma posed by sex selected abortion is that many feminists, not all of whom are women, consider choice in abortion to underpin women's moral agency and the defence of their self determination. A leading modern analyst has observed that:
Whatever the specific reasons are for abortion, most feminists believe that the women concerned are in the best position to judge whether abortion is the appropriate response to pregnancy. Because usually only the woman choosing abortion is properly situated to weigh all the relevant factors, most feminists resist attempts to offer general, abstract rules for determining when abortion is morally justified... . Despite the diversity of opinion found among feminists on most other matters, most feminists agree that women must gain full control over their own reproductive lives if they are to free themselves from male dominance. $^{7}$

Sex selected abortion, however, is seen as an instrument and consequence of male dominance that feminists are committed to oppose. It has been observed that " $[\mathrm{m}]$ any feminists view any efforts to plan the sex of future children as epitomising sexism" ${ }^{8}$ Writing about abortion in 1986, a prominent prochoice advocate stated: "we believe abortionfor-gender choice is an unqualified moral wrong". ${ }^{9}$ Opposition to means of sex selection that are made possible by PGD and sperm sorting avoids the dilemma posed by sex selected abortion, and affords opponents the support of conservative antiabortion agencies, as well as of others committed to the elimination of the pro-male sexism that sex selection is seen to represent.

The stereotypical concept that promale sexism is inherent in sex selection, rooted in perceptions of pervasive devaluation of girl children, may be contradicted in particular countries, however, by empirical studies. For instance, summarising the conclusion of a comprehensive sociological survey and public presentations, members of the Royal Commission on New Reproductive Technologies in Canada reported in 1993 that:

The survey revealed that, contrary to what has been found in some other countries, a large majority of Canadians do not prefer children of one sex or the other. Many intervenors . . . assumed that Canadians have a pro-male bias with regard to family composition; we found that this assumption appears to be unfounded. ${ }^{10}$

Interest in sex determination was found to be very low, and concerned only with family balancing. The commissioners reported regarding sex preferences that: 
Preferences were generally seen as unimportant, almost trivial. The survey showed that virtually all prospective parents want, and feel strongly about having, at least one child of each sex. ${ }^{11}$

Nevertheless, invoking perceived feminist values, the commissioners recommended criminalisation of the use of sex selection techniques, which is now proposed in the legislation introduced in May 2002.

This legislation is comparable to that enacted in India in 1994, but raises the ethical issue of whether the social circumstances the legislation is intended to affect are comparable. The ethical principle of justice, considered at a formal or abstract level, requires that like cases be treated alike, and that different cases be treated with due recognition of the difference; that is, it is as unjust and unethical to treat different cases alike as to treat alike cases differently. ${ }^{12}$ Male dominance may be comparable in Canada and India, but the evidence is that sex preference between children is different.

There may be the same preference in some families for a firstborn child to be male, but this preference, if offensive to equal priority and opportunity between the sexes, can be addressed by permitting sex selection only for second or subsequent children, rather than by absolute prohibition. Under a limit of this nature, allowing sex selection for purposes of family balancing in countries in which no demonstrable pro-male sex bias exists among prospective parents appears at least ethically neutral and tolerable. ${ }^{13}$ Support lies in such tolerance contributing to respect for prospective parents autonomy. It avoids the harm of compelling a woman's repeated pregnancies until her goal of a family balanced by children of both sexes is achieved, and of abortion of an unplanned pregnancy that may be of a fetus of the balancing sex.

Selection based on sex is clearly sexual, but not necessarily sexist. The analogy is with the contrast between racist and racial choice. It is as objectionable for a decision to be sexist as for it to be racist. A racially based decision may be founded, however, on ethical preference, not unethical attribution of inferior status to non-preferred races. For instance, a person's choice to marry a partner of his or her own race may be based on the comfort of common culture and the wish for racially compatible children, not hostility to miscegenation or the belief that races other than one's own are inferior. Similarly, the intention of a couple with a child of one sex to have another child of the other sex is a sexual but not a sexist preference. To suppose that any such choice is necessarily sexist is unjust, and to base laws introducing criminal penalties on such a supposition where the evidence is that an assumption of "a pro-male bias ... appears to be unfounded" ${ }^{\prime 10}$ is both unjust and oppressive.

Where social practice, including that to do with sex selection, is apparently sexist, such as in the environment to which the Indian legislation of 1994 is a response, the ethics of legal prohibition also warrant attention. Since "[f]eminist ethics demands that the effects of any decision on women's lives be a feature of moral discussion and decision making," and focuses "on the need to develop a moral analysis that fits the actual world in which we live ${ }^{\prime \prime}{ }^{14}$ legal prohibition may be examined in that light.

Until their society remedies its son preference, the prohibition of sex selection would seem predominantly to burden women's lives. If wives cannot resist their husbands', and family and religious demands that they deliver sons, they may have to bear successive pregnancies until they do. Early marriage and a quick succession of pregnancies contribute significantly to the risk of maternal mortality and morbidity. A leading gynaecologist has observed that "[e]very woman who gets pregnant is exposed to risk ... The risk increases in low resource settings .... Risks of pregnancy and childbirth recur with every pregnancy. The lifetime risk of pregnancy and childbirth depends on how many times the woman gets pregnant". ${ }^{15}$ Without considering aggravated risks of adolescent pregnancy, a World Health Organisation (WHO) report notes "the disturbing statistics of maternal mortality for developing countries, where women are more than 400 times as likely to die from complications during pregnancy than women in Southern Europe". ${ }^{16}$ The risk to unplanned girl children is of early death due to infanticide, malnutrition, or neglect. ${ }^{17}$

Son preference has produced, but might also mitigate, the sex-ratio imbalance. The latest Indian census puts the national sex ratio as 933 females to 1000 males, but only 927 females in the age group under six years old. In Haryana state, moreover, there are 861 girls to 1000 boys, and only 820 females in the under six age group. ${ }^{18}$ While ominous for the present generation of children, these figures offer a promise of future redress. If sons wish, as adults, to have their own sons, they need wives. The dearth of prospective wives will, in perhaps short time, enhance the social value of daughters, reversing their vulnerability and the force of male dominance.
Whether or not this promise is realised, attempts to end son preference by prohibition of sex selection are failing in India, and appear too peripheral on their own, to relieve sex bias, since "the tail cannot wag the dog". Sex bias must be tackled at more fundamental and comprehensive social, economic, political, and legal levels. Prohibitions are unnecessary and oppressive where there is no sex bias but only a wish to balance a family with children of both sexes, and pose risks to women's and girl children's lives and health where bias remains.

J Med Ethics 2002;28:335-336

\section{Author's affiliations}

Correspondence to: Professor B M Dickens, Faculty of Law, University of Toronto, 84 Queen's Park, Toronto, Ontario, Canada M5S 2C5; bernard.dickens@utoronto.ca

\section{REFERENCES AND NOTES}

1 Niddah 3: 31A. In: Epstein I, ed. The Babylonian Talmud [Slotki IW, trans]. London: Soncino Press, 1948:217

2 Kevles DJ, Hood L, eds. The code of codes: scientific and social issues in the human genome project. Cambridge MA: Harvard University Press, 1992: 251

3 Council of Europe. Convention for the protection of human rights and dignity of the human being with regard to the application of biology and medicine: convention on human rights and biomedicine. Strasbourg: Council of Europe, Directorate of Legal Affairs, 1996.

4 The proposed Assisted Human Reproduction Act, section 5(1)(e).

5 Kleegman SJ, Kaufman SA. Infertility in women. Philadelphia: F A Davis, 1966: 178. 6 For instance the Feminist International Network of Resistance to Reproductive and Genetic Engineering (FINNRAGE), formed in Sweden in 1985

7 Sherwin S. No longer patient: feminist ethics and health care. Philadelphia: Temple University Press, 1992: 102-3.

8 Wolf SM, ed. Feminism and bioethics: beyond reproduction. New York: Oxford University Press, 1996: 336

9 Harrison BW. Feminist realism. Christianity and Crisis 1986;46:233-6.

10 Royal Commission on New Reproductive Technologies. Proceed with care: final report of the royal commission. Ottawa: Minister of Government Services, 1993: 889

11 See reference 10: 890 .

12 Beauchamp TL, Childress JF. Principles of biomedical ethics [5th ed]. New York: Oxford University Press, 2001: 226-30.

13 Pennings G. Ethics of sex selection for family balancing: family balancing as a morally acceptable application of sex selection. Human Reproduction 1996;1 1:2339-45.

14 See reference 7: 55

15 Fathalla MF. From obstetrics and gynecology to women's health: the road ahead. New York: Parthenon, 1997: 122.

16 Department of Reproductive Health and Research, World Health Organisation. Progress in Reproductive Health Research 2001;56:1.

17 Fathalla MF. The girl child. International Journal of Gynecology and Obstetrics 2000;70:7-12, at 8.

18 Registrar General. Provisional population totals, census of India, 2001. New Delhi: Office of the Registrar General, 2001; see also Dugger CW. A claim to help choose baby's sex sets off furore in India. New York Times 2001 Nov 23; sect a: 21. 